\title{
DETECTION OF CARDIAC TISSUES TOXICITY CAUSED BY MONOSODIUM GLUTAMATE AND THE PROTECTIVE ROLE OF VITAMIN C BY IMMUNOHISTOCHEMICAL METHOD, HEART TISSUE OXIDATIVE STRESS BIOMARKERS AND CARDIAC DYSFUNCTION BIOMARKERS
}

\author{
Dalia Abd Elwhab Hassana, Mostafa Abdallah Abdel Alima, Souty M.Z. Sharkawi ${ }^{\text {b }}$ \\ Shimaa Nabil ${ }^{\mathrm{c}}$

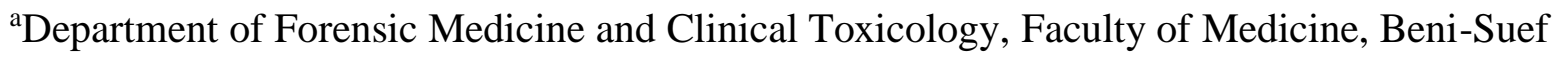 \\ University, Beni-Suef, 62514 Egypt. \\ ${ }^{b}$ Department of Pharmacology and Toxicology, Faculty of Pharmacy, Beni-Suef University, \\ Beni-Suef, 62514 Egypt. \\ ${ }^{c}$ Department of pathology, Faculty of Veterinary Medicine, Beni-Suef University, Beni-Suef, \\ 62514Egypt.
}

The author for correspondence: Dalia Abd Elwahab Hassan

Tel: 01092373209

E-mail address: daliaabdelwahabhassan@gmail.com

\begin{abstract}
Objectives: Monosodium Glutamate (MSG) is one of the world's most extensively used food additives which are ingested as part of commercially processed foods. MSG is a slow excitotoxin food additive which can cause generation of numerous amounts of free radicals which affects many organs such as heart. Vitamin $C$ is an antioxidant protects the body against oxidative stress. Methodology: the experiment was carried out on 100 albino rats weighing about (150-200) g. The animals randomly were divided into equal 4 groups ( $n=25 /$ group). The first group was served as control, the second group was administered oral doses of Vit.C $(200 \mathrm{mg} / \mathrm{Kg})$, the third group was administered oral doses of Monosodium Glutamate (MSG) dissolved in distilled water equal to $60 \mathrm{mg} / \mathrm{kg}$ daily $(60 \mathrm{mg} / \mathrm{Kg})$ the fourth group was administered oral doses of Monosodium Glutamate (MSG) dissolved in distilled water equal to $60 \mathrm{mg} / \mathrm{kg}$ daily $(60 \mathrm{mg} / \mathrm{Kg})$ and Vitamin $\mathrm{C}(200 \mathrm{mg} / \mathrm{Kg})$ for 90 days respectively. Heart tissue oxidative stress biomarkers (Glutathione "GSH" and Mucosal Lipid Peroxidation "MDA") were estimated spectrophotometrically. Cardiac dysfunction biomarkers as protein kinase $\mathrm{C}$ (PKC) and troponin-I (Tn-I) were estimated using ELISA. Immunohistochemically, tissues caspase-3 and tumor necrosis factor- alpha (TNF- $\alpha$ ) were estimated. Histopathology: Samples from heart were fixed in Formalin 10\% for $48 \mathrm{~h}$. Routine histological procedures followed by routine hematoxylin and eosin stain and Masson's trichrome stains for collagen identification. Results: In control negative and vitamin $\mathrm{C}$ group, a normal histological structure of cardiac muscles could be found. Vitamin $\mathrm{C}$ administration corrected the disturbances caused by MSG. Conclusions: MSG may produce oxidative stress via the generation of highly toxic oxygen and nitrogen free-radicals and the inhibition of several antioxidant enzymes, altering several physiological and functional changes in the heart; this resembles human myocardial infarction, which causes sudden death in humans. Vitamin $\mathrm{C}$ administration showed their cardiac protective effects.
\end{abstract}

KEY WORDS: Vitamin C; monosodium glutamate; tumor necrosis factor- alpha (TNF$\alpha$ ); caspase-3; cardiovascular.

ABBREVIATIONS: MSG: Monosodium Glutamate, MDA: Malondialdehyde, GSH: Reduced glutathione, TNF- $\alpha$ : Tumor necrosis factor- alpha, PKC: Protein kinase C. 


\section{INTRODUCTION}

Food additives are products added to the basic food stuffs with an aim of improving its aspect, flavor, taste, color, texture, food value and conservation (Imane et al., 2011). They are making population to like a wide range of wholesome and tasty foods (Amin et al., 2010). The use of preservatives in food industry has been increased with the advancement in the production technologies. Monosodium glutamate (MSG) is a food additive, popularly used all over the world as flavor enhancer. It increases the deliciousness of food and thus increases food consumption (Manal and Nawal, 2012). It is used to flavor meat, poultry, sauces, and soups (Egbuonu et al., 2009). Monosodium glutamate is water soluble and ionized into glutamate (Glu) and $\mathrm{Na}^{+}$in the water at body temperature. Glutamate causes stimulation of glutamate receptors in the mammalian central nervous which playing an important role in both physiological and pathological processes (Mattson, 2008; Ganong, 2005). Monosodium glutamate can work as an "excitotoxin;", which makes over stimulation of nerve cells which may lead to death (Bojanic et al., 2004). Also, Monosodium glutamate leads to free radicals' generation, proteases, phospholipases activation and endonucleases apoptotic programs activation and genes toxicity in rats (Farombi and Onyema, 2006). Virtually all members of the Glu receptor family are involved in excitotoxicity. Glu receptors are expressed in peripheral tissues, as cardiac tissues. These receptors activation induces oxidative stress and apoptosis in cardiac tissues (Howard P. Et al, 2015).

Vitamin C (ascorbic acid) has an antioxidant defensive role through reactive oxygen types and peroxides reduction (Loo et al., 2003). So, it can neutralize these radicals and stop the chain reaction propagation (Manal and Nawal, 2012).

This study were searching for probable harmful effect of MSG, as a natural ingredient of some food substance, on the heart tissue of rats and to estimate the probable effectiveness of vitamin $\mathrm{C}$, as an accessible not expensive antioxidant to reverse this toxicity.

\section{MATERIALS AND METHODS}

\section{Experimental animals:}

100 Adult male and female albino rats with (150-200) $\mathrm{g}$ from The National Research Centre in Egypt, were housed in well ventilated room of temperature $\left(25^{\circ} \mathrm{c}\right)$, $12 \mathrm{~h}$ light $/ 12 \mathrm{~h}$ dark cycle, and humid conditions. The rats were put in plastic cages under standard hygienic conditions, supplied with enough standard rat chow pellets and drinking tap water Ad libidum. To optimize treatment doses, all rats were fasted $1 \mathrm{~h}$ before giving the treatment. We had an approval from "the Ethics Committee of the Faculty of Pharmacy, Beni-Suef University" on the procedures of the study. "The guidelines for the care and use of laboratory animals" which confirmed by the National Institutes of Health Guide and Use of Laboratory Animals (NIH Publications No. 8023, revised 1978) were followed in the all steps of the study. ( The national academies press, Washington, D.C.)

\section{Chemicals:}

Monosodium glutamate (E621) which used in this study was of food-grade packages, while other chemical reagents and solvents were of analytical grade type. Vitamin $\mathrm{C}$ was obtained from El-Kahira Pharm., Chem. Co. Egypt. MSG was obtained from El Nasr Pharm. Chem. Co., Egypt, the reduced glutathione (GSH). Ellman's reagent, thiobarbituric acid (TBA) and N-(1-naphthyl) ethylenediaminedihydrochloride (NEDD) from Sigma-Aldrich (St. Louis, MO, USA).

\section{Experimental design:}

The 100 adult albino rats wear randomly divided to four groups (25/cage):

I group: were normal healthy rats with a daily oral dose of distilled water administration with a dose volume of $1 \mathrm{ml} / 100 \mathrm{~g}$ of body weight. 
II group: Vitamin C orally administration in a daily dose of (200 $\mathrm{mg} / \mathrm{Kg} /$ day). /day,

III group: received $\mathrm{MSG} 60 \mathrm{mg} / \mathrm{kg}$

IV group: oral doses of Monosodium Glutamate (MSG) administration dissolved in distilled water equal to $60 \mathrm{mg} / \mathrm{kg}$ daily $(60 \mathrm{mg} / \mathrm{Kg})$ and Vitamin $\mathrm{C}(200 \mathrm{mg} / \mathrm{Kg})$ for 90 days respectively. (Hamza and AlHarbi, 2014)

Experimental duration was three months and rats were observed daily for general conditions.

\section{Blood samples:}

At the end of treatment period, blood samples were collected; Serum was separated and at $-80^{\circ} \mathrm{C}$ for biochemical study. Then, Animals were killed and hearts were harvested. Thereafter, each tissue was cut into two parts. Part was fixed in $10 \%$ formalin buffered-saline to examine it histopathologically and making immunohistochemical analysis and The other part was homogenized in ice-cooled phosphate buffer saline $(\mathrm{PBS} ; 0.1 \mathrm{M}, \mathrm{ph}=$ 7.4) to obtain a $10 \%$ homogenate, centrifuged for $10 \mathrm{~min}$ at $2000 \mathrm{xg}$ using a cooling centrifuge (Beckman model L3-50, USA), at $-20^{\circ} \mathrm{C}$ for estimations of the biomarkers.

Biochemical assay:

Determination of oxidative stress markers (GSH, MDA):

Hearts TBARS concentration was calculated colorimetrically in n-Butanol at 520-535 $\mathrm{nm}$ according to Uchiyama and Mihara (1978). Also GSH concentration was estimated colorimetrically using Ellman's reagent according to Sedlak and Lindsay (1968).

\section{Determination protein kinase $\mathbf{C}$ and troponin:}

ELISA kits were used for Biochemical estimations of protein kinase $\mathrm{C}$ and troponin.

Immunohistochemical analysis:

For immunohistochemical staining, slides were deparaffined and rehydrated in
PBS followed by blocking the endogenous peroxidase with 3\% hydrogen peroxide. Slides were pretreated with protein block um before incubation with primary antibodies. Caspase-3 "primary antibodies "at the concentration of 1:10 (E-8 code number: sc-7272) and tumor necrosis factor alpha (TNF- $\alpha$, 4E1, code number: sc-130349) were used. Visualization of the immune-reaction was carried out with 3.3'diaminobenzidine. Finally, sections were counterstained with hematoxylin.

\section{Morphometrical analysis:}

Morphometrical analysis of stained Masson's trichrome sections and positive immunohistochemical reactions for caspase-3 TNF- $\alpha$ were carried. An area percentage measurement of the collagen contents was the main parameter for morphometrical analysis which stained green and positive immunohistochemical reactions which appeared brown.

Statistical Analysis:

Results obtained from this experiment were articulated as means \pm S.E. The significant differences among values were analyzed by (one-way ANOVA) with (SPSS) for windows version 10.0. Differences considered significant at $\mathrm{P} \leq$ 0.05 level of significance.

\section{RESULTS \\ Oxidative stress markers (MDA and GSH) activity:}

Administration of MSG in rats showed a significant increase in cardiac MDA levels, coupled with significantly decreased in GSH - level compared to normal control rats. Pre-treatment with vitamin C (200mg/kg/day) simultaneously with MSG significantly decreased cardiac MDA level and increased in GSH level. These results are shown in table (1).

Protein kinase $\mathbf{C}$ and troponin activity:

The effect of vitamin C on PKC and Tn-I activity in rats were evaluated by ELISA. As shown in table (2), rats that given MSG showed increase in protein kinase $\mathrm{C}$ and troponin when compared with normal control group. However, 
pretreatment with vitamin $\mathrm{C}$ (200mg/kg/day) simultaneously with MSG significantly down regulated activity as compared to MSG group. These results showed that vitamin $\mathrm{C}$ effectively improved MSG-induced heart injury (Table 2).

\section{Histopathological and \\ Immunohistochemical examination:}

In normal control rats and vitamin $\mathrm{C}$ treated rat, heart sections showed normal histological appearance (Fig 1a, 1b). MSGintoxicated rat heart sections showed severe degenerative changes and necrosis of cardiac muscles accompanied with focal lymphocytic infiltration (Fig 1c). Pretreatment of rats with vitamin $\mathrm{C}$ (200mg/kg/day) simultaneously with MSG significantly counteracted MSG effect and showed moderate lesions, in the form of moderate hyalinossis and minimal lymphocytic myocarditis as shown in Fig $1 d$.

Accordingly, Masson's trichromestained sections revealed the presence of collagen fibers proliferation with green color in hearts. The highest level of collagen fibers proliferation could be detected in MSG group with a percentage of $5.5 \%$ (Fig. 2c). A normal distribution of collagen fibers was seen in the normal control and vitamin $\mathrm{C}$ groups with percentages of 1.5 and $1.94 \%$ respectively with no significant difference (Fig. 2a and $2 b$ ). In pretreatment of rats with vitamin $C$ (200mg/kg/day) simultaneously with MSG the percentages of collagen fiber was decreased to each $3.9 \%$ (Fig. 2b).

Immunohistochemical examination of heart tissues showed the percentages of caspase- 3 and TNF- $\alpha$ in all groups, the highest percentages was found in MSG group (Fig. 3c and 4c) with a significant difference with all groups. The lowest area percentages were found in normal control and vitamin $\mathrm{C}$ groups with no significant difference between them (Figs. 3a, 3b, 4a and $4 \mathrm{~b}$ ). The area percentages of positive immunoreactivity were statistically decreased in rats treated with vitamin $\mathrm{C}$ (200mg/kg/day) simultaneously with MSG in comparison with MSG group (Fig.3d and $4 d)$.

Table (1): Effects of vitamin C on cardiac MDA and GSH contents on MSG induced heart injury in rats.

\begin{tabular}{|l|l|l|}
\hline Groups Parameters & $\begin{array}{l}\text { MDA } \\
(\mathrm{nmol} / \mathrm{gm} \text { tissue })\end{array}$ & $\begin{array}{l}\text { GSH } \\
(\mu \mathrm{mol} / \mathrm{gm} \text { tissue })\end{array}$ \\
\hline Normal Control & $18.60 \pm 1.37^{\mathrm{a}}$ & $15.20 \pm 1.77^{\mathrm{a}}$ \\
\hline Vitamin C $(200 \mathrm{mg} / \mathrm{kg} / \mathrm{day})$ & $14.30 \pm 1.10^{\mathrm{a}}$ & $16.20 \pm 0.64^{\mathrm{a}}$ \\
\hline MSG $(60 \mathrm{mg} / \mathrm{kg} / \mathrm{day})$ & $47.60 \pm 0.55$ & $11.20 \pm 0.25$ \\
\hline Vitamin C + MSG & $12.90 \pm 4.12^{\mathrm{a}}$ & $18.50 \pm 0.57^{\mathrm{a}}$ \\
\hline
\end{tabular}

Data are expressed as mean \pm standard deviation of six rats. Statistical comparisons between values were analyzed for statistical significance using one-way ANOVA followed by NewmanKeuls test and denoted by $p<0.05$.

a Values are significantly different from MSG group.

Table 2: Effects of vitamin C on PKC and Tn-I level on MSG induced heart injury in rats.

\begin{tabular}{|l|l|l|}
\hline \multicolumn{1}{|c|}{ Parameters } & $\begin{array}{l}\text { PKC } \\
(\mathrm{pg} / \mathrm{ml})\end{array}$ & $\begin{array}{l}\text { Tn-I } \\
(\mathrm{pg} / \mathrm{ml})\end{array}$ \\
\hline Normal Control & $11.70 \pm 0.84^{\mathrm{a}}$ & $12.50 \pm 0.73^{\mathrm{a}}$ \\
\hline Vitamin C (200mg/kg/day) & $11.40 \pm 0.33^{\mathrm{a}}$ & $12.50 \pm 0.39^{\mathrm{a}}$ \\
\hline MSG (60 mg/kg/day) & $14.10 \pm 0.46$ & $15.30 \pm 0.25$ \\
\hline Vitamin C + MSG & $11.20 \pm 0.16^{\mathrm{a}}$ & $12.00 \pm 0.37^{\mathrm{a}}$ \\
\hline
\end{tabular}


Data are expressed as mean \pm standard deviation of six rats. Statistical comparisons between values were analyzed for statistical significance using one-way ANOVA followed by NewmanKeuls test and denoted by $p<0.05$.

a Values are significantly different from MSG group.

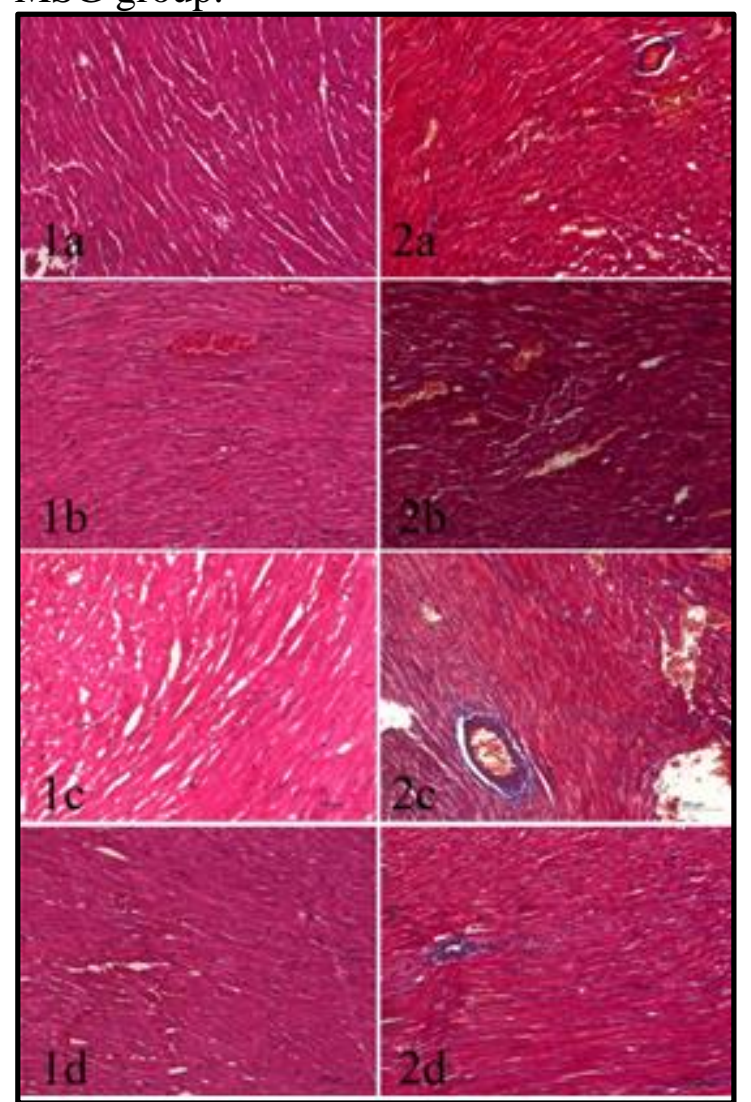

Figures (1) and (2): Photomicrographs of cardiac sections obtained from different groups stained with $\mathrm{H} \& \mathrm{E}$.

(Fig. 1) Fig1c shows severe degenerative changes and necrosis of cardiac muscles accompanied with focal lymphocytic infiltration and Masson's trichrome stains (Fig. 2) showing the effect of vitamin $\mathrm{C}$ administration (200 mg/kg/day) on MSGinduced heart injury in rats (H\&E stain; 200x). Photo a: Normal control section, showing normal cardiac myocytes; normal distribution of collagen fibers Photo $b$ : vitamin $\mathrm{C}$ section, showing normal cardiac no histopathological changes, normal distribution of collagen fibers photo c: section from MSG treated rats showing severe degenerative changes and necrosis of cardiac muscles accompanied with focal lymphocytic infiltration and presence of collagen fibers proliferation with green color in hearts. Photo d: sections from MSG and vitamin $C$ treated rat, showing improved histologic appearance.

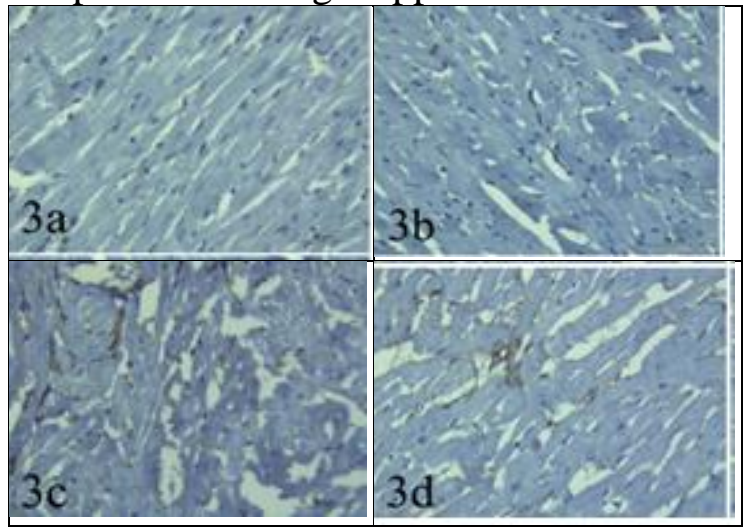

Figure (3): Immunohistochemical examination of the effect of vitamin $C$ administration (200 $\mathrm{mg} / \mathrm{kg} / \mathrm{day})$ on MSG-induced heart injury in rats on heart tissue caspase-3expression.

Photo 3a: Normal control caspase-3 expression; Photo 3b: vitamin $\mathrm{C}$ caspase- 3 expression; photo 3c: expression of caspase-3 from MSG treated rats Photo $3 \mathrm{~d}$ : expression of caspase- 3 from MSG and vitamin $\mathrm{C}$ treated rat. The highest percentages of caspase- 3 and TNF- $\alpha$ was found in MSG group (Fig. 3c). The lowest area percentages were found in normal control and vitamin $\mathrm{C}$ groups with no significant difference between them (Figs. $3 a, 3 b)$. The area percentages of positive immunoreactivity were statistically decreased in rats treated with vitamin $\mathrm{C}$ (200mg/kg/day) simultaneously with MSG in comparison with MSG group (Fig.3d).

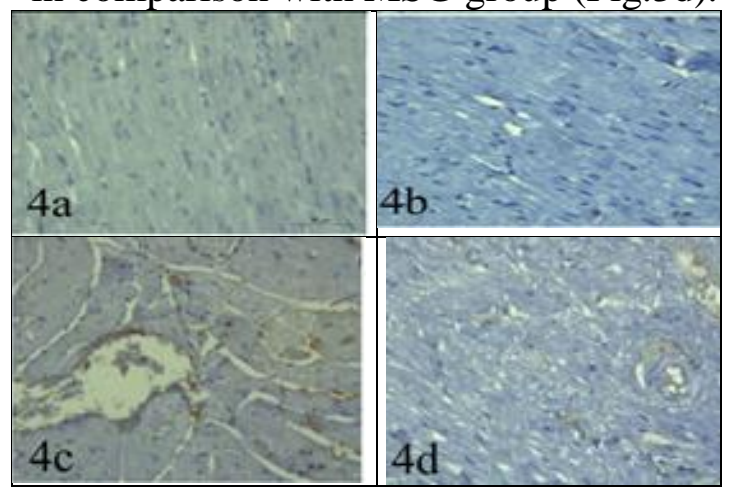

Figure (4): Immunohistochemical examination of the effect of vitamin $C$ administration (200 $\mathrm{mg} / \mathrm{kg} / \mathrm{day})$ on 


\section{MSG-induced heart injury in rats on heart tissue TNF-aexpression.}

Photo 4a: Normal control TNF- $\alpha$ expression; Photo 4b: vitamin C TNFaexpression; photo 4c: expression of TNF$\alpha$ from MSG treated rats Photo $4 \mathrm{~d}$ : expression of TNF- $\alpha$ from MSG and vitamin $\mathrm{C}$ treated rat. The highest percentages of caspase- 3 and TNF- $\alpha$ was found in MSG group (Fig. 4c). The lowest area percentages were found in normal control and vitamin $\mathrm{C}$ groups with no significant difference between them (Figs. $4 \mathrm{a}$ and 4b). The area percentages of positive immunoreactivity were statistically decreased in rats treated with vitamin C (200mg/kg/day) simultaneously with MSG in comparison with MSG group (Fig. 4d).

\section{DISCUSSION}

Assessment of blood constituents of experimental animals as changes from the normal levels due to administration of different products consumed by humans have been continued to play valuable method in studying effects of these products on human health. The extensive use of a great number of food additives has caused toxic effects on human health that need permanent supervision.

Lipid peroxidation is a major indicator of oxidative damage initiated by ROS and causes membrane function impairment. It was explained that MDA rank is increased as a component of lipid peroxidation that happened by ROS action on lipids of cellular membrane (Amin et al., 2010).

In our study, the effect of vitamin $\mathrm{C}$ was studied against MSG-induced heart injury in adult rats. Several studies cleared that receiving of MSG results in freeradicals generation in animals (Farombi and Onyema, 2006). This comes in agreement with this experiment where administration of $\mathrm{MSG}(60 \mathrm{mg} / \mathrm{kg} / \mathrm{day}$, orally) for 90 days resulted in a significant stimulation of reactive oxygen species (ROS) as evidenced by increased heart tissue content of MDA (Table 1). This was coupled with significantly decreased in
GSH content, which is consistent with previous report of Małgorzata Nita and Andrzej Grzybowski, 2016 who cleared that antioxidant deficiency is connected with accumulation of the free radicals and ROS which lead to oxidative damage to mitochondrial DNA which has an significant pathogenic function in organ injure. The outcome of the present study cleared that receiving vitamin $\mathrm{C}$ counteracted MSG-induced tissue oxidative and inflammatory damage evidenced by a significant decrease of MDA level and increase of GSH content to normal levels; in agreement with Farombi and Onyema (2006) who reported that the antioxidants have defensive role against oxidative stress induced by MSG. This explains cardiac oxidative stress that observed in our experiment in MSG rats (Table 1). ROS have been demonstrated to be an early signal mediating apoptosis via activating mitochondrial pathways (Kanter et al., 2005). This also supports our findings where MSG administration significantly increased markers levels of cardiac cell damage as PKC and Tn-I in serum (Table 2). This is can explain by the excessive ROS accumulation can also lead to oxidative DNA damage, resulting in cell cycle process delay (Jeffrey A. and Susan L., 2003). Also, according to the results of this study, vitamin $\mathrm{C}$ administration significantly decreased levels of PKC and Tn-I. These results agree with Pavlovic and Sarac (2010) who stated that vitamin C may significantly restore the MSG-induced oxidative stress and apoptosis in thymus.

In current study, a significant increase in immune-expression of TNF- $\alpha$ and caspase-3was detected in MSG treated group. The over-production of inflammatory cytokines, TNF- $\alpha$ and apoptosis marker ascaspase- 3 is involved in tissue injury (Susana Á. et al., 2011). More interestingly, that vitamin $\mathrm{C}$ remarkably suppressed the activation of TNF- $\alpha$ and caspase- 3 induced by MSG, suggesting that the beneficial effect of vitamin $\mathrm{C}$ on MSG-induced inflammation 
and apoptosis was through downregulating the activation of TNF- $\alpha$ and caspase-3. Our results matched those of Abdel-Daim et al. [2015] and Yavuz et al. [2004]. Also, El-Shitany and El-Desoky (2016), reported that vitamin $C$ has protection effect against azithromycininduced cardio toxicity in rats via decreasing ROS and TNF- $\alpha$ production and inhibiting caspase- 3 expression.

\section{CONCLUSION:}

Monosodium glutamate can create oxidative stress through the highly toxic oxygen and nitrogen free-radicals generation and several antioxidant enzymes inhibition. Increasing in glutamate and glutamine in blood may lead to the significant increase in oxidative stress markers activity which produces lipogenesis. Intracellular accumulation of Glutamate could alter the redox state of the cell, increasing the level of glutamate and the concentration of glutamine which causes toxicity in the heart. MSG can increase inflammation and apoptosis, which altering several cardiac physiological and functional changes, which gives the same picture to human myocardial infarction leading to sudden death. Vitamin $\mathrm{C}$ administration showed their cardio protective effects through their antioxidant, anti-inflammatory, and antiapoptotic effects.

\section{RECOMMENDATIONS}

Further researches on human are needed to investigate harmful effect of MSG on different organs, especially heart. Further studies should be done to clear the pharmacokinetics of vitamin $\mathrm{C}$ especially in overdose administration.

\section{REFERENCES}

Amin, K.A., H. Abdel Hameid and A.H.

AbdElsttar, (2010): Effect of food azo dyes tartrazine and carmoisine on biochemical parameters related to renal, hepatic function and oxidative stress biomarkers in young male rats. Food and Chemical Toxicology, (48): 29942999.
Amira A. Wahdan and Mohamed M. Shareef, (2016): Study of the Protective Effect of Vitamin $\mathrm{C}$ on Monosodium Glutamate Induced Cardiotoxicity in Adult Male Albino Rats. Ain Shams Journal of Forensic Medicine and Clinical Toxicology, 27: 49- 56.

Bojanic V.V., Bojanic Z., Najman S., Ivanov-e urlis J., Tomin J., Dinoic B., Savic T. (2004): Diltiazem prevention of monosodium glutamate toxicity on hypothalamus in Wistar rats. Arch Oncol. 12:19-20.

Egbuonu, A. C. C., O. Obidoa, C. A. Ezeokonkwo, L. U. S. Ezeanyika and P. M. Ejikeme, (2009): Hepatotoxic effects of low dose oral administration of monosodium glutamate in male albino rats. African Journal of Biotechnology, 8 (13): 3031-3035.

El-Shitany NA and El-Desoky K., (2016): Protective Effects of Carvedilol and Vitamin $\mathrm{C}$ against AzithromycinInduced Cardiotoxicity in Rats via Decreasing ROS, IL1- $\beta$, and TNF- $\alpha$ Production and Inhibiting NF- $\kappa \mathrm{B}$ and Caspase-3 Expression. Oxidative Medicine and Cell Longevity journal.

Farombi EO and Onyema OO (2006): Monosodium glutamate-induced oxidative damage and genotoxicity in the rat: Modulatory role of vitamin $\mathrm{C}$, vitamin $\mathrm{E}$ and quercetin. Hum Exp Toxicol. 25: 251-259

G. R. Buettner, (1993): "The Packing Order of Free Radicals and Antioxidants: Lipid Peroxidation, aTocopherol and As- corbate," Archives of Biochemistry, 157: 375-380.

Ganong, W. F., (2005): Review of medical physiology, 25th ed., Lange Med. Public. Chapter,(17):267-302.

Hamza .RZ and Al- Harbi MS. (2014): monosodium glutamate induced testicular toxicity and the possible ameliorative role of vitamin $\mathrm{E}$ or selenium in male rats. Toxicology reports; 1037-1045.

Howard Prentice, Jigar Pravinchandra Modi and Jang-Yen Wu, (2015): 
Mechanisms of Neuronal Protection against Excitotoxicity, Endoplasmic Reticulum Stress, and Mitochondrial Dysfunction in Stroke and Neurodegenerative Diseases. Oxidative Medicine and Cell Longevity journal.

Imane, H., Said B., Faiza S., Fatima B., Mohammed A., Mohamed B., Jouhar Z., Zolikha B. and Hassane M., E. Saalaoui, (2011): A 90 day oral toxicity study of Tartrazine, a synthetic food dye, in wistar rat. International Journal of Pharmacy and Pharmaceutical Science, 3(3):159-169.

Jeffrey A. Klein and Susan L. Ackerman, (2003): Oxidative stress, cell cycle, and neurodegeneration. $\mathrm{J}$ Clin Invest. 15; 111(6): 785-793.

Jozef Sedlak, Raymond H. Lindsay, (1968): Estimation of total, proteinbound, and nonprotein sulfhydryl groups in tissue with Ellman's reagent. Analytical Biochemistry, 25, 195-205.

M. Kanter, O. Coskun, F. Armutcu, Y. H. Uz and G. Kizilay, (2005): "Protective Effects of Vitamin C, Alone or in Combination with Vitamin A, on Endotoxin-Induced Oxidative Renal Tissue Damage in Rats," The Tohoku Journal of Experimental Medicine, 206, 2,155-162.

M. M. Abdel-Daim, E. W. Ghazy, and M. Fayez, (2015): "Synergistic protective role of mirazid (Commiphora molmol) and ascorbic acid against tilmicosin-induced cardiotoxicity in mice," Canadian Journal of Physiology and Pharmacology, 93, 1, 45-51.

Malgorzata Nita and Andrzej Grzybowski, (2016): The Role of the Reactive Oxygen Species and Oxidative Stress in the Pathomechanism of the Age-Related Ocular Diseases and Other Pathologies of the Anterior and Posterior Eye Segments in Adults. Oxidative Medicine and Cellular Longevity.
Manal, S.T. and N. Al-Badr, (2012): Adverse Effects of Monosodium Glutamate on Liver and Kidney Functionsin Adult Rats and Potential Protective Effect of Vitamins C and E. Food and Nutrition Sciences, (3): 651659.

Mihara, M. and Uchiyama, M., (1978): Determination of Malonaldehyde Precursor in Tissues by Thiobarbituric Acid Test. Analytical Biochemistry, 86, 271-278.

Nagy S. Tawfek, Hanan M. Amin, Abdalla A. Abdalla, Shimaa H. M. Fargali, (2015): Adverse Effects of Some Food Additives in Adult Male Albino Rats. Current Science International journal, 4 (4) : 525-537.

Onyema, O. O., A. C. Sylvanus and I. A. Peace, (2012): Monosodium Glutamate Induces Oxidative Stress and Affects Glucose Metabolism in the Kidney of Rats. International Journal of Biochemistry Research \& Review, 2(1): 1-11.

Pavlovic V. and Sarac M., (2010): The role of ascorbic acid and monosodium glutamate in thymocyte apoptosis. Bratisl Lek Listy. ;111(6):357-60.

Susana Á lvarez, Almudena Blanco, Manuel Fresno, Ma Ángeles MuñozFernández, (2011): TNF- $\alpha$ Contributes to Caspase-3 Independent Apoptosis in Neuroblastoma Cells: Role of NFAT. plos one journal.

T. Yavuz, I. Altuntas, N. Delibas et al., (2004): "Cardiotoxicity in rats induced by methidathion and ameliorating effect of vitamins E and C," Human and Experimental Toxicology, 23, 7, 323329, 204.

The national academies press. Washington, D.C, (2011): The guidelines for the care and use of laboratory animals declared by the National Institutes of Health Guide and Use of Laboratory Animals. $8^{\text {th }}$ edition. 


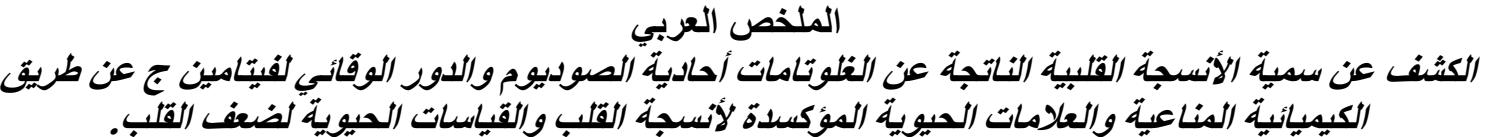

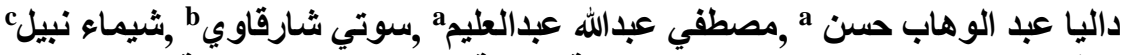

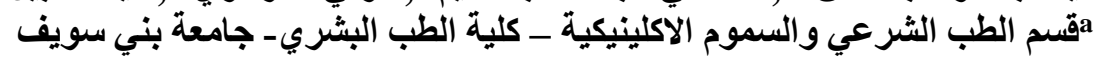

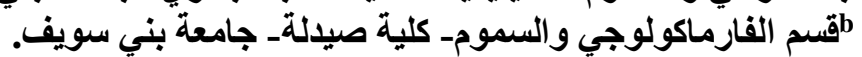

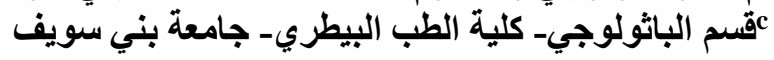

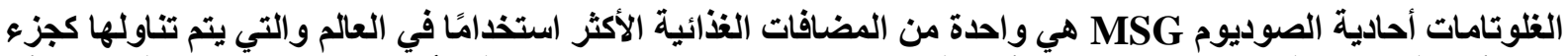

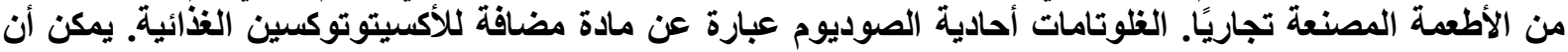

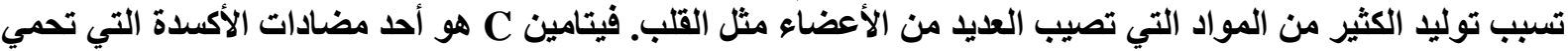

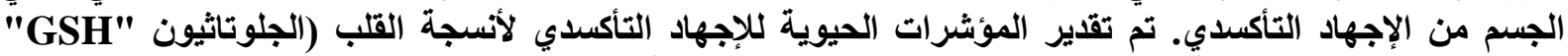

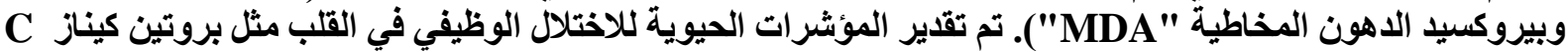

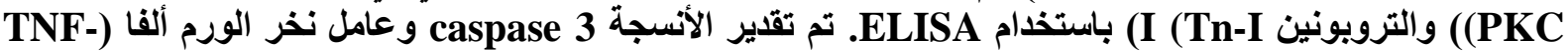

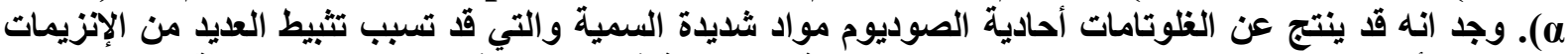

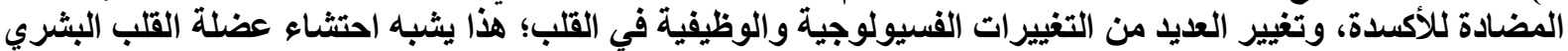

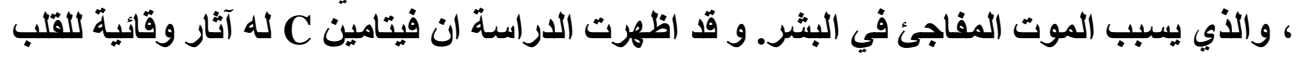

